\title{
Characteristics of visits and predictors of admission from a paediatric emergency room in Saudi Arabia
}

\author{
Mohammad H. Al-Qahtani ${ }^{1,2}$, Abdullah A. Yousef ${ }^{1,2}$, Bassam H. Awary ${ }^{1,2}$, Waleed H. Albuali, ${ }^{1,2}$, \\ Mohammed A. Al Ghamdi, ${ }^{1,2}$, Reem S. AlOmar ${ }^{3 *}$, Nouf A. AlShamlan ${ }^{3}$, Haneen A. Yousef ${ }^{3}$, Sameerah Motabgani ${ }^{3}$, \\ Naheel A. AlAmer ${ }^{3}$, Kawthar M. Alsawad ${ }^{4}$, Fatimah Y. Altaweel ${ }^{4}$, Kawther S. Altaweel ${ }^{4}$, Roaya A. AlQunais ${ }^{4}$, \\ Fatima A. Alsubaie ${ }^{4}$ and Malak A. Al Shammari ${ }^{3}$
}

\begin{abstract}
Background: The Emergency Room (ER) is one of the most used areas in healthcare institutions. Problems with over utilisation and overcrowding have been reported worldwide. This study aims at examining the characteristics of paediatric ER visits, the rate of hospital admissions and its associated predictors at King Fahd Hospital of the University in the Eastern Province of Saudi Arabia.

Methods: This is a retrospective, medical record-based study. Variables included gender, age group, nationality, complaints, Triage level, shifts and seasons. Descriptive statistics were reported as frequencies/percentages. P-values were obtained through a Chi-Squared test while unadjusted and adjusted odds ratios were estimated by binary logistic regression, where admission was considered as the outcome.

Results: The total number of paediatric patients included was 46,374 , and only $2.5 \%$ were admitted. Males comprised $55.4 \%$ while females comprised $44.6 \%$. The most common age group were toddlers, and $92.4 \%$ of the total sample were Saudis. The most common complaint was fever (26.9\%) followed by respiratory symptoms (24.9\%). Only 7 patients (0.02\%) were classified as triage I (Resuscitation), and most were triage IV (Less urgent) (71.0\%). Most visits occurred during the winter months. Adjusted ORs showed that neonates had higher odds of admission $(\mathrm{OR}=3.85,95 \% \mathrm{Cl}=2.57-5.76)$. Moreover, those presenting with haematological conditions showed an OR of $65.49(95 \% \mathrm{Cl}=47.85-89.64)$, followed by endocrine conditions showing an OR of $34.89(95 \% \mathrm{Cl}=23.65-51.47)$. Triage I had a very high odds of admission $(O R=19.02,95 \% \mathrm{Cl}=2.70-133.76)$, whereas triage $\mathrm{V}$ was associated with a very low odds of admission ( $\mathrm{OR}=0.30,95 \% \mathrm{Cl}=0.23-0.38$ ).
\end{abstract}

Conclusions: A low rate of hospital admission was found in comparison with other rates worldwide. This was mostly attributed to an alarmingly high number of non-urgent ER visits. This further emphasises the problem with improper use of ER services, as these cases should be more appropriately directed towards primary healthcare centres. Further studies to examine the impact of prioritising patients in the ER based on the identified predictors of hospital admission, in addition to the standard triage system, are suggested.

Keywords: Paediatric, Emergency room, Admissions, Saudi Arabia

\footnotetext{
* Correspondence: rsomar@iau.edu.sa

${ }^{3}$ Department of Family and Community Medicine, Imam Abdulrahman Bin University, Dammam, Saudi Arabia

Full list of author information is available at the end of the article
}

(c) The Author(s). 2021 Open Access This article is licensed under a Creative Commons Attribution 4.0 International License, which permits use, sharing, adaptation, distribution and reproduction in any medium or format, as long as you give appropriate credit to the original author(s) and the source, provide a link to the Creative Commons licence, and indicate if changes were made. The images or other third party material in this article are included in the article's Creative Commons licence, unless indicated otherwise in a credit line to the material. If material is not included in the article's Creative Commons licence and your intended use is not permitted by statutory regulation or exceeds the permitted use, you will need to obtain permission directly from the copyright holder. To view a copy of this licence, visit http://creativecommons.org/licenses/by/4.0/ The Creative Commons Public Domain Dedication waiver (http://creativecommons.org/publicdomain/zero/1.0/) applies to the data made available in this article, unless otherwise stated in a credit line to the data. 


\section{Background}

The Emergency Room (ER) remains one of the most utilised areas for paediatric patients in healthcare institutions. It continues to suffer from prolonged length of stay, overcrowding and extended waiting hours, all of which may lead to adverse events [1]. This is especially the case in Saudi Arabia (SA), where the ER may still be considered the main point of entrance to the healthcare system [2].

Paediatric ER visits vary worldwide. For example, in the US, it comprised an estimated $20 \%$ of all ER visits. In SA, children were reported to comprise $32.6 \%$ of all ER visits in a tertiary hospital in the Capital city of Riyadh [3].

The Canadian Triage and Acuity Scale (CTAS) has been implemented in almost all tertiary care hospitals in SA. The scale is used to manage and prioritise patients according to the severity of their condition and is based on five levels. It ensures that patients who are critically ill or injured are attended to before the less ill or injured patients [4]. The implementation of this system highlighted the significant problem in which patients arrive at the ER with non-urgent and mild conditions where they would have been more appropriately seen by a primary care physician.

According to recent research of one tertiary hospital in SA, $78.5 \%$ of visits to the ER were of non-urgent cases [5]. Another research which looked into three tertiary hospitals in SA found that non-urgent cases comprised $53 \%$ of all ER visits and examining paediatric ER visits specifically, non-urgent cases ranged between 35.9 and $59.5 \%[6,7]$.

This problem has been a focus of the government lead by the Ministry of Health, in which an attempt has been made to reform the healthcare system by including primary healthcare services in its reform strategy for 20102020. The strategy aimed at increasing the number and quality of primary care centres including its preventive services. Additionally, more programmes and initiatives for the Saudi Vision 2030 focus on public health and primary healthcare services [8].

This study aims at assessing the characteristics of paediatric ER visits, as well as estimating the rate of admissions and its predictors in one large teaching hospital in the Eastern Province of SA.

\section{Methods}

\section{Study setting and design}

Following ethical approval, we conducted this retrospective study at King Fahd Hospital of the Imam Abdulrahman Bin Faisal University in the Eastern Province of SA. The Paediatrics' ER contains 7 observation beds, 2 examination rooms, 1 triage room, a waiting area, and a minor surgical room. Major trauma cases are treated in the resuscitation room (for both adults and paediatrics). Paediatric ER is supported by pharmacy, radiology services, and the ability to refer the patient for admission as needed. The ER staff is made up of six qualified paediatric emergency consultants, as well as eight paediatric specialists devoted to emergency coverage. This is in addition to rotating paediatric program residents in different levels, one each month. The initial triage in the registration area is done by a qualified nurse while the paediatric ER triage is done by the assigned paediatric nurse and the rotating residents. The ER staff work in three shifts to cover the $24 \mathrm{~h}$, these are the morning shift (8:00 am-16:00 pm), the evening shift (pm 16:00-00:00 $\mathrm{am}$ ), and the night shift (am 00:00-8:00 am). To cover the needs in the morning and night shifts, there are two to four physicians, and two to four nurses except for the evening shift where there is a minimum of three physicians. Some shifts also involve rotating interns and students for training and teaching.

\section{Study population}

The study included all patients presented to the paediatric ER, aged from 1 day to $<14$ years old between the 1st of January 2018 and the 31st of December 2018. According to the hospital's policy, the paediatric department is responsible for patients who fall within this age range.

\section{Data collection}

A structured data collection sheet to collect data from the patient's electronic medical records was used. Data included information about patient's age, sex, season in which the patient presented in, chief complaint - as reported by the caregiver and categorised by the involved system, which shift received the patient, and whether admission to the hospital ward was ordered. These variables were chosen based on the study objectives as well as the literature and availability of the data.

\section{Statistical analysis}

The age groups were allocated as the following: neonates ( $<29$ days), infants ( 29 days -1 year), toddlers ( $>1$ year -3 years), pre-schoolers ( $>3$ years -6 years), schoolers $(>6$ years-12 years) and adolescents ( $>12$ years-14 years). Nationality as: Saudis and non-Saudis. The time of visits was grouped based on the season; Winter (December, January, February), Spring (March, April, May), Summer (June, July, August), and Autumn (September, October, November). Shifts were divided into three groups: morning (8:00 am-16:00 pm), evening shift (pm 16:00-00:00 $\mathrm{am}$ ), and night shift (am 00:00-8:00 am). The chief complaints were categorized according to the system involved. The triage categories were according to the CTAS implemented in the hospital, in which I is for resuscitation, II for emergent, III for urgent, IV for less urgent, and $\mathrm{V}$ for non-urgent [4]. Descriptive statistics 
were presented as frequencies and percentages. The main outcome was whether the patient was admitted to hospital or not. The Chi-squared test was performed to compute the $P$-values, and statistical significance was set at $P<0.05$. The Bonferroni adjustment was used to adjust for multiple comparisons. Unadjusted and adjusted Odds ratios (ORs) were drawn through multivariable binary logistic regression, where the reference category was the most frequent. The final model was chosen based on appropriate model diagnostics. Statistical analysis was performed in Stata Software 15 Software [9].

\section{Results}

The total number of ER visits by paediatric patients was 46,374 . The sociodemographic characteristics of patients are presented in Table 1 . The sample consisted of $55.4 \%$ males and $44.6 \%$ females. The highest number of visits belonged to the toddlers age group (32.0\%), followed by schoolers (24.9\%). The smallest number of visits were for the neonates $(0.9 \%)$. Most patients were of the Saudi nationality.

The ER characteristics of paediatric patients are presented in Table 2 . Of the total sample, only $2.5 \%$ of patients were admitted. The highest number of complaints recorded was for fever followed by respiratory symptoms (27.0 and $24.9 \%$ respectively). With regards to triage, only $0.02 \%$ were for triage I and $0.02 \%$ for triage II, whereas triage IV and V made up 71.0 and $26.2 \%$ of the visits. Most visits occurred in the evening shift and the winter season had the highest rate of visits (31.9\%).

When exploring the association between sociodemographic characteristics and admissions, the age group variable was found to be highly statistically associated with admissions $(P<0.001)$. Analysing this further,

Table 1 Sociodemographic characteristics of paediatric patients 2018

\begin{tabular}{ll}
\hline Characteristic & $\mathbf{N}(\%)$ \\
\hline Sex & $\mathbf{4 6 , 3 7 4 ( 1 0 0 )}$ \\
Males & $25,675(55.4)$ \\
Females & $20,699(44.6)$ \\
Age group & \\
Neonates (> 29 days) & $408(00.9)$ \\
Infants (29>11 months) & $6813(14.7)$ \\
Toddler (1-3 years) & $14,833(32.0)$ \\
Pre-schooler (4-6years) & $9498(20.5)$ \\
Schooler (7-12 years) & $11,580(24.9)$ \\
Adolescent (13-14 years) & $3242(07.0)$ \\
Nationality & \\
Saudi & $42,825(92.4)$ \\
Non-Saudi & $3549(07.6)$ \\
\hline
\end{tabular}

Table 2 ER visit characteristics of paediatric patients during 2018

\begin{tabular}{|c|c|}
\hline Characteristic & $\begin{array}{l}N(\%) \\
46,374(100)\end{array}$ \\
\hline \multicolumn{2}{|l|}{ Admission } \\
\hline Yes & $1134(02.5)$ \\
\hline No & $45,240(97.5)$ \\
\hline \multicolumn{2}{|l|}{ Complaints } \\
\hline Cardiology & $75(00.2)$ \\
\hline Dental & $231(00.5)$ \\
\hline Dermatology & $1751(03.8)$ \\
\hline Endocrine & $202(00.4)$ \\
\hline ENT & $2975(06.4)$ \\
\hline Fever & $12,492(27.0)$ \\
\hline Genitourinary & $377(00.8)$ \\
\hline $\mathrm{Gl}$ & $7078(15.3)$ \\
\hline Haematology & $327(00.7)$ \\
\hline Ophthalmology & $1028(02.2)$ \\
\hline Musculoskeletal & $499(00.9)$ \\
\hline Neurology & $462(01.0)$ \\
\hline Respiratory & $11,554(24.9)$ \\
\hline Surgery & $377(00.8)$ \\
\hline Toxicology & $387(00.8)$ \\
\hline Trauma & $5212(11.2)$ \\
\hline Others & $1447(03.1)$ \\
\hline \multicolumn{2}{|l|}{ Triage } \\
\hline I & $7(0.02)$ \\
\hline$\|$ & $10(0.02)$ \\
\hline III & $1242(02.6)$ \\
\hline IV & $32,931(71.0)$ \\
\hline V & $12,184(26.2)$ \\
\hline \multicolumn{2}{|l|}{ Shift } \\
\hline Morning & $13,649(29.4)$ \\
\hline Evening & $21,568(46.5)$ \\
\hline Night & $11,157(24.1)$ \\
\hline \multicolumn{2}{|l|}{ Season } \\
\hline Winter (December, January, February) & $14,800(31.9)$ \\
\hline Spring (March, April, May) & $11,563(25.0)$ \\
\hline Autumn (September, October, November) & $11,970(25.8)$ \\
\hline Summer (June, July, August) & $8041(17.3)$ \\
\hline
\end{tabular}

comparisons between all age groups were statistically significant, except for adolescents with other age groups. Further, the rate of admission was not found to be different between males and females (Table 3).

Associations between ER visit characteristics and admission are presented in Table 4 . The presenting complaints, triage and shifts were found to be highly 
Table 3 Associations between admissions and sociodemographic characteristics of paediatric ER patients during 2018

\begin{tabular}{|c|c|c|c|}
\hline \multirow[t]{2}{*}{ Characteristic } & \multicolumn{2}{|l|}{ Admission } & \multirow[t]{2}{*}{$P$-value } \\
\hline & $\begin{array}{l}\text { No } \\
45,240(97.55)\end{array}$ & $\begin{array}{l}\text { Yes } \\
1134(02.45)\end{array}$ & \\
\hline Sex & & & 0.91 \\
\hline Males & $25,049(97.6)$ & $626(02.4)$ & \\
\hline Females & 20,191 (97.5) & $508(02.5)$ & \\
\hline Age group & & & $<0.001$ \\
\hline Neonates (> 29 days) & $371(90.9)$ & $37(09.1)$ & \\
\hline Infants (29 > 11 months) & $6572(96.5)$ & $241(03.5)$ & \\
\hline Toddler (1-3 years) & $14,536(98.0)$ & $297(02.0)$ & \\
\hline Pre-schooler (4-6 years) & $9334(98.3)$ & $164(01.7)$ & \\
\hline Schooler (7-12 years) & $11,265(97.3)$ & $315(02.7)$ & \\
\hline Adolescent (13-14 years) & $3162(97.5)$ & $80(02.5)$ & \\
\hline Nationality & & & 0.44 \\
\hline Saudi & $41,771(97.5)$ & $1054(02.5)$ & \\
\hline Non-Saudi & 3469 (97.7) & $80(02.3)$ & \\
\hline
\end{tabular}

statistically associated with admissions at the $P<0.001$ level. The Endocrine and Haematological complaints, as well as triage group $\mathrm{V}$, were found to have contributed mostly to the high statistically significant $p$-value when compared to other groups following multiple comparison testing. For shifts, the only statistical difference was found for the comparison between the evening and the morning shift (Bonferroni adjusted $p$-value $<0.001$ ). No significant association was observed for the season.

The unadjusted and adjusted ORs of admissions in relation to the sociodemographic and ER visit characteristics are presented in Table 5 . The analysis shows that before and after adjusting for other variables, there is higher odds of admission for both neonates and infants, although the risk is almost fourfold for neonates (Adjusted $\mathrm{OR}=3.85$, $95 \% \mathrm{CI}=2.57-5.76$ and Adjusted $\mathrm{OR}=1.89,95 \% \mathrm{CI}=1.56-$ 2.28 respectively). With regards to the complaint, the highest odds of admission were for haematological illnesses both before and after adjustment, followed by endocrinal conditions when compared to fever which is statistically significant. In comparison with triage IV, triage I had a 19.02 OR for admission, followed by triage II $(\mathrm{OR}=10.66$, $95 \% \mathrm{CI}=1.98-57.23)$. Triage $\mathrm{V}$ had the lowest odds of admission both before and after adjustment and was statistically significant (Adjusted $\mathrm{OR}=0.30,95 \% \mathrm{CI}=0.23-0.38$ ). Morning shifts were associated with a relatively high odd of admission, although they were not significant after adjustment, and neither were the seasons of the visit.

Figure 1 shows the number of admissions by month of visits. It can be seen that the lowest numbers of admission were during July and August, whereas the highest were for January, February and March.
Table 4 Associations between admissions and ER visit characteristics of paediatric ER patients during 2018

\begin{tabular}{|c|c|c|c|}
\hline \multirow[t]{2}{*}{ ER visit characteristics } & \multicolumn{2}{|l|}{ Admission } & \multirow[t]{2}{*}{$P$-value } \\
\hline & $\begin{array}{l}\text { No } \\
45,240(97.55)\end{array}$ & $\begin{array}{l}\text { Yes } \\
1134(02.45)\end{array}$ & \\
\hline Complaint & & & $<0.001$ \\
\hline Cardiology & $71(94.7)$ & $4(05.3)$ & \\
\hline Dental & $231(100.0)$ & 0 & \\
\hline Dermatology & $1735(99.1)$ & $16(00.9)$ & \\
\hline Endocrine & $133(65.8)$ & $69(34.2)$ & \\
\hline ENT & $2950(99.2)$ & $25(00.8)$ & \\
\hline Fever & $12,375(99.1)$ & $117(00.9)$ & \\
\hline Genitourinary & $356(94.4)$ & $21(05.6)$ & \\
\hline Gl & $6920(97.7)$ & $158(02.3)$ & \\
\hline Haematology & $193(59.0)$ & $134(41.0)$ & \\
\hline Ophthalmology & $1021(99.3)$ & $7(00.7)$ & \\
\hline Musculoskeletal & $395(99.0)$ & $4(01.0)$ & \\
\hline Neurology & $422(91.3)$ & $40(08.7)$ & \\
\hline Respiratory & $11,250(97.4)$ & $304(02.6)$ & \\
\hline Surgery & $360(95.5)$ & $17(04.5)$ & \\
\hline Toxicology & $358(92.5)$ & $29(07.5)$ & \\
\hline Trauma & 5085 (97.6) & $127(02.4)$ & \\
\hline Others & 1385 (95.7) & $62(04.3)$ & \\
\hline Triage & & & $<0.001$ \\
\hline I & $3(42.9)$ & $4(57.1)$ & \\
\hline$\|$ & $7(70.0)$ & $3(30.0)$ & \\
\hline III & $1063(85.6)$ & $179(14.4)$ & \\
\hline IV & $32,068(97.4)$ & $863(02.6)$ & \\
\hline V & 12,099 (99.3) & $85(00.7)$ & \\
\hline Shift & & & $<0.001$ \\
\hline Morning & $13,263(97.2)$ & $386(02.8)$ & \\
\hline Evening & 21,099 (97.8) & $469(02.2)$ & \\
\hline Night & $10,878(97.5)$ & $279(02.5)$ & \\
\hline Season & & & 0.93 \\
\hline Winter (Dec, Jan, Feb) & $14,432(97.5)$ & $368(02.5)$ & \\
\hline Spring (Mar, Apr, May) & 8266 (97.6) & $199(02.4)$ & \\
\hline Autumn (Sep, Oct, Nov) & $11,679(97.6)$ & $291(02.4)$ & \\
\hline Summer (Jun, Jul, Aug) & $7846(97.6)$ & 195(02.4) & \\
\hline
\end{tabular}

\section{Discussion}

This study supports the evidence that paediatric ERs are very much being used by patients as the first point of contact with the healthcare system, rather than visiting their local primary health care physician. This is a problem which should have eased with the current governmental initiative in promoting the use of primary healthcare. 
Table 5 Unadjusted/adjusted ORs of admissions according to sociodemographic/ER visit characteristics of paediatric patients during 2018

\begin{tabular}{|c|c|c|c|}
\hline \multirow[t]{2}{*}{ Characteristics } & \multicolumn{3}{|l|}{ Risk of admission } \\
\hline & Unadjusted OR (95\%Cl) & & Adjusted OR $(95 \% \mathrm{Cl})$ \\
\hline \multicolumn{4}{|l|}{ Sex } \\
\hline Males & & Reference & \\
\hline Females & $1.00(0.89-1.13)$ & & $1.06(0.93-1.20)$ \\
\hline \multicolumn{4}{|l|}{ Age group } \\
\hline Neonates (> 29 days) & $4.88(3.41-6.97)$ & & $3.85(2.57-5.76)$ \\
\hline Infants (29 > 11 months) & $1.79(1.51-2.13)$ & & $1.89(1.56-2.28)$ \\
\hline Toddler ( $1-3$ years) & & Reference & \\
\hline Pre-schooler (4-6 years) & $0.85(0.70-1.04)$ & & $0.91(0.74-1.13)$ \\
\hline Schooler (7-12 years) & $1.36(1.16-1.60)$ & & $1.09(0.90-1.31)$ \\
\hline Adolescent (13-14 years) & $1.23(0.96-1.58)$ & & $0.84(0.63-1.12)$ \\
\hline \multicolumn{4}{|l|}{ Complaint ${ }^{a}$} \\
\hline Cardiology & $5.95(2.14-1.64)$ & & $2.61(0.75-9.11)$ \\
\hline Dermatology & $0.97(0.57-1.64)$ & & $1.16(0.68-1.98)$ \\
\hline Endocrine & $54.87(38.93-77.33)$ & & $34.89(23.65-51.47)$ \\
\hline ENT & $0.89(0.58-1.38)$ & & $1.15(0.71-1.58)$ \\
\hline Fever & & Reference & \\
\hline Genitourinary & $6.23(3.87-10.04)$ & & $6.66(4.08-10.86)$ \\
\hline $\mathrm{Gl}$ & $2.41(1.89-3.07)$ & & $2.06(1.60-2.66)$ \\
\hline Haematology & 73.43 (55.17-97.73) & & 65.49 (47.85-89.64) \\
\hline Ophthalmology & $0.72(0.33-1.55)$ & & $0.86(-.39-1.86)$ \\
\hline Musculoskeletal & $1.07(0.39-2.91)$ & & $1.04(0.32-3.32)$ \\
\hline Neurology & $10.02(6.91-14.54)$ & & $6.19(4.07-9.43)$ \\
\hline Respiratory & $2.85(2.30-3.54)$ & & $2.65(2.12-3.32)$ \\
\hline Surgery & $4.99(2.97-8.39)$ & & $5.42(3.14-9.35)$ \\
\hline Toxicology & $8.56(5.62-13.03)$ & & $4.50(2.82-7.15)$ \\
\hline Trauma & $2.64(2.05-3.40)$ & & $2.30(1.75-3.02)$ \\
\hline Others & $4.73(3.46-6.47)$ & & $4.78(3.38-6.76)$ \\
\hline \multicolumn{4}{|l|}{ Triage } \\
\hline । & $49.54(11.07-221.70)$ & & $19.02(2.70-133.76)$ \\
\hline$\|$ & $15.92(4.11-61.98)$ & & $10.66(1.98-57.23)$ \\
\hline III & $6.25(5.26-7.43)$ & & $4.08(3.30-5.04)$ \\
\hline IV & & Reference & \\
\hline V & $0.26(0.20-0.32)$ & & $0.30(0.23-0.38)$ \\
\hline \multicolumn{4}{|l|}{ Shift } \\
\hline Morning & $1.30(1.14-1.50)$ & & $1.14(0.98-1.32)$ \\
\hline Evening & & Reference & \\
\hline Night & $1.15(0.99-1.34)$ & & $1.10(0.93-1.30)$ \\
\hline \multicolumn{4}{|l|}{ Season } \\
\hline Winter (Dec, Jan, Feb) & & Reference & \\
\hline Spring (Mar, Apr, May) & $0.94(0.79-1.12)$ & & $0.83(0.69-0.99)$ \\
\hline Autumn (Sep, Oct, Nov) & $0.97(0.83-1.14)$ & & $0.94(0.79-1.10)$ \\
\hline Summer (Jun, Jul, Aug) & $0.97(0.81-1.16)$ & & $0.84(0.69-1.01)$ \\
\hline
\end{tabular}

${ }^{a}$ Dental category dropped in regression analyses due to zero counts 


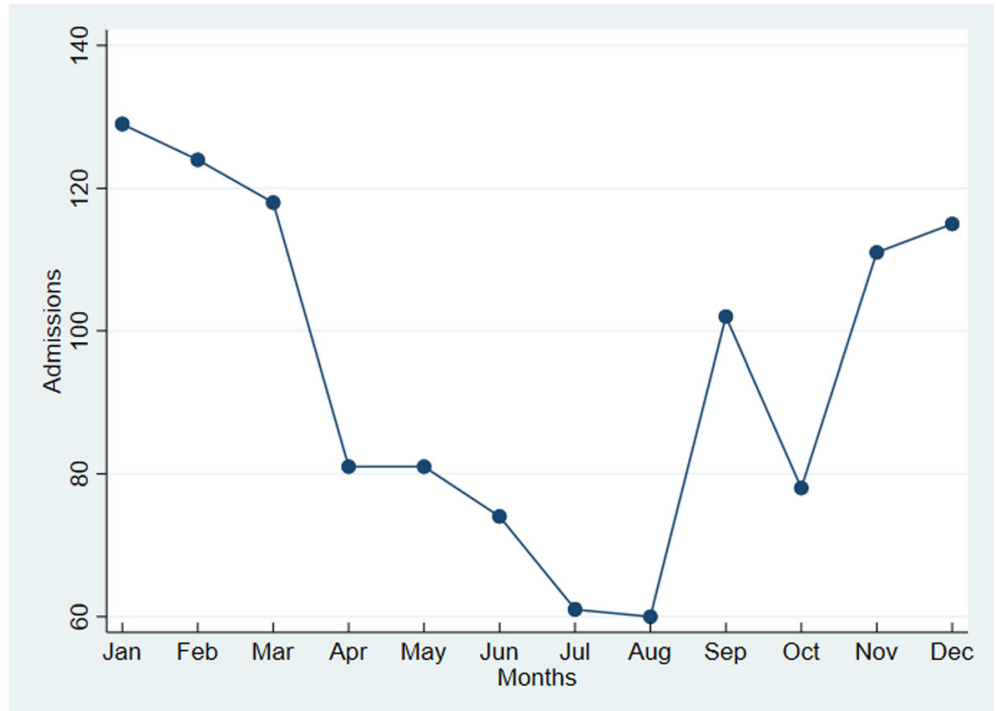

Fig. 1 Number of admissions from ER paediatric visits during 2018

\section{Characteristics of paediatric ER visits}

Within this data, it was found that the most common paediatric age group was for toddlers aged between $1<$ 3 years. Similar distributions have been found in other paediatric ERs in the US [10], Lebanon [11], and in another Saudi hospital located at the capital city of Riyadh [12]. Toddlerhood is a critical period where children start crawling, walking, learning to run, climbing, and jumping. Therefore, they may be prone to accidents or minor injuries. Moreover, the least common age group in our data were neonates, which is in sharp contrast to data from Pakistan which found that neonates had the highest rate of visits [13]. Cultural differences may have played a role where mothers attempt to treat theirs infants with herbal medicines or over the counter medications when they display certain symptoms such as infantile colic rather than presenting their child to a doctor [14].

Fever was the highest presenting complaint in our data. This is similar to other studies in Thailand and Lebanon [11, 15]. Fever is a general complaint and may be a sign of a wide spectrum of illnesses which may explain how it became the most common presenting complaint. Like the Thailand study [15], respiratory symptoms were the second most common complaint, which usually presents in the form of coughing, sneezing and difficulty in breathing. Such symptoms may be brought by air pollution, second-hand smoking or more strongly by changes in weather. Indeed, our findings show that weather has been found to play a role in the rates of ER visits. The highest number of visits were found to be during the winter, in November and December, but more specifically in January. Higher winter visits are mainly due to the common viral infections occurring in this period such as bronchitis, viral upper respiratory tract infections as well as complicated viral infections superimposed with bacterial infections. On the other hand, the summer season had the lowest number of visits. Prior to the COVID-19 epidemic, families tend to travel abroad during this season [16]. Other studies have also found similar patterns to that of our analysis both locally and internationally [12, 15]. Two Saudi studies, one based in Riyadh (1997) and the other in the Eastern region (2007), have found that non-urgent cases belonging to triage IV and V comprised between 35.9 and $59.5 \%$ of ER visits [6, 7]. Although, these two studies have been published a long time ago, the issue remains persistent and is worsening. Approximately two thirds of our patients were classified in Triage category IV, indicating they are non-urgent cases which may have been better dealt with in a primary care setting. To date, parents and patients in general in SA still prefer to seek medical services in the ER. Possible explanations may have to do with a lack of knowledge of a primary care centre near their home, long appointment hours in the primary care centre, dissatisfaction with the primary care physician, accessibility issues or even a perception that the condition is urgent and warrants medical attention straight away $[5,17,18]$. The management of such nonurgent cases in the ER increases the burden on the ER staff which may subsequently affect the quality of care that should be reserved for the high priority cases.

\section{Admissions and their associated factors}

The admission rate of paediatric ER cases in this study was $2.45 \%$. It is similar to the $3.3 \%$ rate of admission reported in the US [19], but much smaller than that reported in 
Lebanon, South Korea, and Pakistan, where the rates were reported to be $9.8,14.3$ and $45 \%$ respectively $[11,13,20]$. A systematic review by Obermeyer et al. (2015) assessed emergency care in low and middle-income countries and found that the median paediatric admission rate was $22 \%$ [21]. Comparing it with the admission rate from this study further emphasizes the role of primary care centres in accommodating the vast majority of patients presenting in the ER. Similar to the South Korean study [20], we found no significant differences in admission rates between males and females.

Unlike studies conducted in the US, Lebanon, Pakistan and Egypt, analyses here have shown that the neonate age group had the highest odds of admission, even though they were the smallest number with regards to ER visits [11, 13, 22, 23]. Differences in rates may be attributed to the different disease prevalence in these countries which may be affected by genetics, accessibility and the type of healthcare provided in hospitals. A further explanation to the higher odds of admission of neonates could be related to the hospital regulations and protocols to rule out neonatal sepsis [24].

Haematological conditions also had the highest odds of admissions. The Saudi population, especially those residing in the Eastern Province, which this data is derived from, are known to have a high prevalence of sickle cell disease (SCD) in children [25]. The prevalence of genetic haematological diseases in SA may be lowered by educating new prospective couples and enforcing recommendations by premarital counselling, as they are yet to be obligatory. Our data contrasts with that of Pakistan and Nigeria, where respiratory complaints had the highest rate of admissions [13, 26]. In Lebanon, complaints related to cardiology were the highest [11].

Furthermore, Triage I was associated with the highest odds of admission in these patients. Similar patterns were found in a US study, although the Emergency Severity Index level was used rather than CTAS [27]. Triage $\mathrm{V}$ was associated with lower odds of admission, which again highlights that the ER may suffer from overcrowding due to the presentation of non-urgent cases.

Neither the shift nor the season of the paediatric patients visiting the ER had any association with the rates of admission. It may be of notice that Spring, Autumn and Summer, despite their non-statistical significance, did show lower odds of admission when compared to Winter. In Australia, high and low temperatures were significantly associated with an increase in paediatric ER admissions [28], this was also noted in the UK [29]. Higher admission rates in low temperatures may be explained by children being more prone to cold weather viruses that could subsequently cause bronchiolitis in under 2 years olds and ultimately lead to an increased ER admission [30].
Several limitations with this study have been identified. The study is based on retrospective medical records drawn from a single healthcare institution, which may compromise the generalisability of the results. Also, despite the large number of data, some confidence estimates were wide which may be due to the extremely small number of cases within cells.

\section{Conclusion}

This study examined paediatric ER visits at a large teaching hospital in the Eastern Province of SA. It showed that the admission rate of ER visits is extremely low. It also showed that neonates, patients with haematological conditions and patients classified as triage I had the highest odds of admission. However, patients classified as triage $\mathrm{V}$ had lower odds of admission. Clear guidance should be used to inform patients and parents of the proper process for seeking medical assistance, as well as ensuring more accessibility to primary health care centres. Moreover, further analysis focused on the predictors identified in this research is highly recommended to inform hospital administrators of potential minor changes that could lead to significant reduction in the over utilisation of the ER.

\section{Abbreviations}

ER: Emergency room; SA: Saudi Arabia; CTAS: Canadian triage and acuity scale

\section{Acknowledgments}

Authors are thankful for the medical and non-medical staff at King Fahd Hospital of the University, Eastern Province, Saudi Arabia.

\section{Authors' contributions}

MHA, AAY, BHA, WHA, MAA, RSA, NAA conceived the study. KMA, FYA, KSA, RAA, and FAA retrieved and prepared the data for analysis. RSA and NAA designed and conducted the study. NAA, MOA, HAA, SMM wrote the first draft of the manuscript. All others read and approved the final version of the manuscript.

\section{Funding}

There are no funding sources to declare.

\section{Availability of data and materials}

The data used in this study were obtained from the electronic medical records of patients and are not publicly available. However, a request may be put to Paediatric Department Head Dr. Abdullah A Yousef who is a coauthor in this study.

\section{Declarations}

Ethics approval and consent to participate

This study was approved by the Institutional Review Board of Imam Abdulrahman Bin Faisal University (IRB: UGS-2019-01-298). Administrative permission to access patients' records was sought from the Paediatric Department Head Dr. Abdullah A Yousef. Informed consent was waived since no identifiable personal data were used. We confirm that all methods were carried out in accordance with relevant guidelines and regulations.

Consent for publication

Not appliable.

Competing interests

The authors declare they have no competing interests. 


\section{Author details}

'Department of Paediatrics, Imam Abdulrahman Bin Faisal University, College of Medicine, Dammam, Saudi Arabia. ${ }^{2}$ King Fahd Hospital of the University, Al-Khobar, Saudi Arabia. ${ }^{3}$ Department of Family and Community Medicine, Imam Abdulrahman Bin University, Dammam, Saudi Arabia. ${ }^{4}$ College of Medicine, Imam Abdulrahman bin Faisal University, Dammam, Saudi Arabia.

Received: 16 January 2021 Accepted: 4 June 2021

Published online: 21 June 2021

\section{References}

1. Kubicek K, Liu D, Beaudin C, Supan J, Weiss G, Lu Y, et al. A profile of nonurgent emergency department use in an urban pediatric hospital. Pediatr Emerg Care. 2012;28(10):977-84.

2. Khattab E, Sabbagh A, Aljerian N, Binsalleeh H, Almulhim M, Alqahtani A et al. Emergency medicine in Saudi Arabia: a century of progress and a bright vision for the future. Int J Emerg Med. 2019;12(1):16.

3. Elkum NB, Barrett C, Al-Omran H. Canadian emergency DepartmentTriage and acuity scale: implementation in a tertiary care center in Saudi Arabia. BMC Emerg Med. 2011;11(1):3.

4. Lee JY, Oh SH, Peck EH, Lee JM, Park KN, Kim SH, et al. The validity of the Canadian Triage and Acuity Scale in predicting resource utilization and the need for immediate life-saving interventions in elderly emergency department patients. Scand J Trauma Resusc Emerg Med. 2011;19:68.

5. Al-Otmy SS, Abduljabbar AZ, Al-Raddadi RM, Farahat F. Factors associated with non-urgent visits to the emergency department in a tertiary care Centre, western Saudi Arabia: cross-sectional study. BMJ Open. 2020;10(10): e035951.

6. Rehmani $R$, Norain A. Trends in emergency department utilization in a hospital in the eastern region of Saudi Arabia. Saudi Med J. 2007;28(2): 236-40.

7. Al-Ayed IH, Shaikh JA, Qureshi MI. Patterns of pediatric emergency room visits at King Khalid University Hospital. Riyadh Annals Saudi Med. 1997; 17(3):360-2.

8. Asmri MA, Almalki MJ, Fitzgerald G, Clark M. The public health care system and primary care services in Saudi Arabia: a system in transition. East Mediterr Health J. 2020;26(4):468-76.

9. StataCorp: Stata Statistical Software: Release 16. In. College Station, TX StataCorp LLC; 2017.

10. Massin MM, Montesanti J, Gérard P, Lepage P. Spectrum and frequency of illness presenting to a pediatric emergency department. Acta Clin Belg. 2006;61(4):161.

11. El Zahran T, El Warea M, Bachir R, Hitti E. The Pediatric Disease Spectrum in an Emergency Department at a Tertiary Care Center in Beirut, Lebanon. Pediatr Emerg Care. 2018;

12. Alhusain F, Alhassan N, Aljohi W, Alrumaih F, Aljerian N, Alharthy N. Paediatric emergency department during the holidays: findings from a 10year analysis of visit rates and trauma patterns. J Health Specialties. 2017;5: 142.

13. ljaz N, Strehlow M, Ewen Wang N, Pirrotta E, Tariq A, Mahmood N, et al. Epidemiology of patients presenting to a pediatric emergency department in Karachi. Pakistan BMC Emerg Med. 2018;18(1):22.

14. Al-Shehri $H$, Al-Mogheer BH, Al-Sawyan TH, Abualalaa AB, Jarrah $O A$, Jabari $M$, et al. Assessment of maternal knowledge about infantile colic in Saudi Arabia. Electron Physician. 2016;8(12):3313-7.

15. Pandee U, Vallipakorn SA, Plitponkarnpim A. The Profile of Pediatric Patients Visit Emergency Department at Urban University Hospital in Thailand. J Med Assoc Thai. 2015:98(8):761-7.

16. The Volume of the Expenditure on the Inbound Tourism Stands at 33.8 Billion Riyals this Year. https://mt.gov.sa/en/mediaCenter/News/MainNews/ Pages/a-m-1-12-9-19.aspx.

17. AlOmar RS, AlShamlan NA, AlAmer NA, AlThumairi AA, Almir BM, Aldawood HA, Bukhamsin TH, Alqahtani HA, Al Shammari MA. Perceived Barriers to Primary Care Services Utilization and its Associations with Overall Satisfaction of Patients in Saudi Arabia: A Cross-Sectional QuestionnaireBased Study. J Prim Care Community Health. 2021;12:21501327211014065.

18. Berry A, Brousseau D, Brotanek JM, Tomany-Korman S, Flores G. Why Do Parents Bring Children to the Emergency Department for Nonurgent Conditions? A Qualitative Study. Ambul Pediatr. 2008:8(6):360-7.
19. Merrill CT, Owens PL, Stocks C. Pediatric Emergency Department Visits in Community Hospitals from Selected States, 2005: Statistical Brief \#52: Agency for Healthcare Research and Quality (US), Rockville (MD); 2006.

20. Seo DH, Kim MJ, Kim KH, Park J, Shin DW, Kim H, et al. The characteristics of pediatric emergency department visits in Korea: an observational study analyzing Korea health panel data. PLoS One. 2018;13(5):e0197929.

21. Obermeyer Z, Abujaber S, Makar M, Stoll S, Kayden SR, Wallis LA, et al. Acute care development C: emergency care in 59 low- and middle-income countries: a systematic review. Bull World Health Organ. 2015;93(8):577$586 \mathrm{G}$.

22. Overview of Pediatric Emergency Department Visits. 2015. https://hcup-us.a hrq.gov/reports/statbriefs/sb242-Pediatric-ED-Visits-2015.jsp.

23. Bazaraa HM, El Houchi S, Rady HI. Profile of patients visiting the pediatric emergency service in an Egyptian university hospital. Pediatr Emerg Care. 2012;28(2):148-52.

24. Gomez B, Mintegi S, Bressan S, Da Dalt L, Gervaix A, Lacroix L. Validation of the "step-by-step" approach in the management of young febrile infants. Pediatrics. 2016;138(2):e20154381.

25. Alhamdan NA, Almazrou YY, Alswaidi FM, Choudhry AJ. Premarital screening for thalassemia and sickle cell disease in Saudi Arabia. Gen Med. 2007;9(6): $372-7$.

26. Enyuma CO, Anah MU, Pousson A, Olorunfemi G, Ibisomi L, Abang BE, et al. Patterns of paediatric emergency admissions and predictors of prolonged hospital stay at the children emergency room, University of Calabar Teaching Hospital, Calabar, Nigeria. Afr Health Sci. 2019;19(2):1910-23.

27. Green NA, Durani Y, Brecher D, DePiero A, Loiselle J, Attia M. Emergency severity index version 4: a valid and reliable tool in pediatric emergency department triage. Pediatr Emerg Care. 2012;28(8):753-7.

28. Xu Z, Hu W, Su H, Turner LR, Ye X, Wang J, et al. Extreme temperatures and paediatric emergency department admissions. J Epidemiol Community Health. 2014;68(4):304-11.

29. McShane P, Draper ES, McKinney PA, McFadzean J, Parslow RC. Effects of out-of-hours and winter admissions and number of patients per unit on mortality in pediatric intensive care. J Pediatr. 2013;163(4):1039-1044.e1035.

30. Murray J, Bottle A, Sharland M, Modi N, Aylin P, Majeed A, et al. Risk factors for hospital admission with RSV bronchiolitis in England: a population-based birth cohort study. PLoS One. 2014;9(2):e89186.

\section{Publisher's Note}

Springer Nature remains neutral with regard to jurisdictional claims in published maps and institutional affiliations.

Ready to submit your research? Choose BMC and benefit from:

- fast, convenient online submission

- thorough peer review by experienced researchers in your field

- rapid publication on acceptance

- support for research data, including large and complex data types

- gold Open Access which fosters wider collaboration and increased citations

- maximum visibility for your research: over $100 \mathrm{M}$ website views per year

At $\mathrm{BMC}$, research is always in progress.

Learn more biomedcentral.com/submissions 